\title{
Environmental controls of giant-kelp biomass in the Santa Barbara Channel, California
}

\author{
Kyle C. Cavanaugh ${ }^{1, *}$, David A. Siegel ${ }^{1,2}$, Daniel C. Reed $^{3}$, Philip E. Dennison ${ }^{4}$ \\ ${ }^{1}$ Earth Research Institute, ${ }^{2}$ Department of Geography, and ${ }^{3}$ Marine Science Institute, University of California, Santa Barbara, \\ California 93106, USA \\ ${ }^{4}$ Department of Geography, University of Utah, Salt Lake City, Utah 84112, USA
}

\begin{abstract}
Synthesizing long-term observations at multiple scales is vital for understanding the environmental drivers of ecosystem dynamics. We assessed the role of several environmental drivers in explaining temporal and spatial patterns in the abundance of giant kelp Macrocystis pyrifera in the Santa Barbara Channel between 1984 and 2009. We developed a novel method for estimating the canopy biomass of giant kelp from Landsat 5 Thematic Mapper satellite imagery, which allowed us to examine the dynamics of giant-kelp biomass on spatial scales ranging from 100s of $\mathrm{m}^{2}$ to $100 \mathrm{~s}$ of $\mathrm{km}^{2}$ and temporal scales ranging from several weeks to $25 \mathrm{yr}$. Comparisons of changes in canopy biomass with oceanographic and climatic data revealed that winter losses of regional kelp canopy biomass were positively correlated with significant wave height $\left(\mathrm{r}^{2}=0.50\right)$, while spring recoveries were negatively correlated with sea surface temperature $\left(\mathrm{r}^{2}=0.30\right.$; used as a proxy for nutrient availability). On interannual timescales, regional kelp-canopy biomass lagged the variations in wave heights, sea surface temperatures, and the North Pacific Gyre Oscillation index by $3 \mathrm{yr}$, indicating that these factors affect cycles of kelp recruitment and mortality. Results from cluster analysis showed that the response of kelp biomass to environmental conditions varied among different subregions of the Santa Barbara Channel. The dynamics of kelp biomass in exposed regions were related to wave disturbance, while kelp dynamics in sheltered regions tracked sea surface temperatures more closely. These results depict a high level of regional heterogeneity in the biomass dynamics of this important foundation species.
\end{abstract}

KEY WORDS: Giant kelp · Spatial and temporal variability $\cdot$ Disturbance $\cdot$ Remote sensing $\cdot$ Long-term data

Resale or republication not permitted without written consent of the publisher

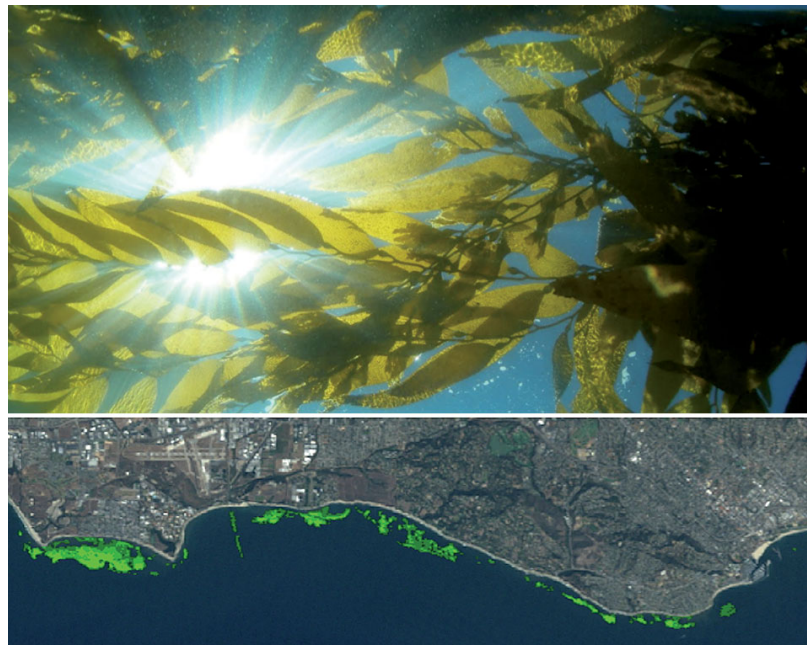

Canopy biomass of Macrocystis pyrifera (top) can be quantified from Landsat 5 imagery (bottom).

Photo: Stuart Halewood

\section{INTRODUCTION}

Climate-related changes in the oceans appear to be accelerating: oceans are becoming warmer and more acidic, nutrient distributions are changing, and, in some regions such as the Northeast Pacific, the frequency and intensity of large storms are increasing (e.g. Easterling et al. 2000, Behrenfeld et al. 2006, Doney et al. 2009). Many marine ecosystems have displayed dramatic responses to recent fluctuations in climate, and accumulating evidence suggests that coastal marine ecosystems are especially vulnerable to the effects of climate change (e.g. Harley et al. 2006, Przeslawski et al. 2008, Hoegh-Guldberg \& Bruno 2010). However, our understanding of how climate- 
induced changes in environmental conditions will affect coastal marine ecosystems is limited. Data collection is labor-intensive and there are relatively few long-term $(>20 \mathrm{yr})$ studies of change in coastal marine ecosystems as compared to terrestrial systems (Rosenzweig et al. 2008). Increasing the number of long-term, largescale data sets of coastal ecosystems is needed to further our understanding of how they are likely to respond to future changes in climate.

Among coastal primary producers, forests of giant kelp Macrocystis pyrifera are particularly sensitive to climate change (Graham et al. 2007). Giant kelp is the world's largest alga and its numerous fronds extend vertically in the water column and form a canopy at the sea surface. The biomass of giant kelp is exceptionally dynamic; short lifespans of both fronds and entire plants ( 4 to 6 mo and 2 to $3 \mathrm{yr}$, respectively) combine with rapid growth $\left(\sim 2 \%\right.$ of total biomass $\left.\mathrm{d}^{-1}\right)$ to produce a standing biomass that turns over 6 to 7 times $\mathrm{yr}^{-1}$ (Reed et al. 2008). Because of such rapid turnover, the biomass dynamics of giant kelp responds quickly to changes in environmental conditions.

Giant-kelp recruitment and growth are controlled by abotic factors, including the availability of hard substrate, solar radiation, and the supply of nutrients, as well as the biotic effects of inter- and intra-species competition for space, light and grazing (reviewed in Graham et al. 2007). In southern California, growth is fastest in winter and spring when nutrient levels are high and competition for light and space is low (due to low algal biomass), and slowest during summer when nutrients are low and competition for light and space is high due to well-developed algal canopies (Zimmerman \& Kremer 1986, Reed et al. 2008). The relatively low capacity of giant kelp to store nutrients $(\sim 30 \mathrm{~d}$, Zimmerman \& Kremer 1986) causes populations to respond rapidly to fluctuations in nutrient supply. Much like growth, the recruitment of giant kelp in southern California and elsewhere responds strongly to fluctuations in nutrients and light as determined by biotic and abiotic processes (Dayton et al. 1984, Reed \& Foster 1984, Reed et al. 2008). Giant kelp produces spores throughout the year (Reed et al. 1996) and the recruitment of new plants typically occurs whenever favorable conditions of light and nutrients coincide (Deysher \& Dean 1986).

Giant-kelp mortality occurs in the form of senescence, grazing, and wave-driven disturbance (Graham et al. 2007). Reed et al. (2008) found that both frond losses and plant mortality were correlated to wave heights in kelp forests near Santa Barbara, California, although correlations were stronger at the plant level. High mortality can also result from prolonged conditions of low nutrients such as those associated with El Niño events (Dayton \& Tegner 1990, Dayton et al.
1999, Edwards 2004). The biomass dynamics of giant kelp reflect the interplay of these physical and biological forcings that control patterns of recruitment, growth, and mortality.

The relative importance of resource availability (light and nutrients) versus physical disturbance (waves) in controlling the biomass dynamics of giant kelp remains an open question. For example, Dayton et al. (1999) found that large-scale, low-frequency changes in nutrient availability had the largest effects on kelp populations in San Diego; however, recent analyses of kelp forests in central and southern California during 2001 to 2009 (a period lacking any major nutrient-poor El Niño conditions) showed that wave disturbance explained more variability in kelp biomass and production than either nutrient availability or grazing (Reed et al. 2008, D. C. Reed et al. unpubl.). It is clear that the apparent influence that each of these physical forcings has on kelp populations is dependent on the spatial and temporal scales of observation (Edwards 2004). While a particular kelp forest may be nutrient-limited at a given time, another forest in a more nutrient-rich region may have its dynamics controlled by wave disturbance. The vast majority of long-term kelp studies have been made at the local scale $\left(<500 \mathrm{~m}^{2}\right)$ and so it has been difficult to test how their conclusions apply to larger areas $\left(>1 \mathrm{~km}^{2}\right)$. In the past, aerial and satellite imagery have been used to examine giant kelp forests at regional scales; however, these studies have generally been either short-term pilot studies (e.g. Deysher 1993, Stekoll et al. 2006) or limited to just a few years (e.g. Donnellan 2004, Cavanaugh et al. 2010), too short a period to examine interannual-to-decadal variability in kelp biomass dynamics. Longer time series (e.g. Parnell et al. 2010) are needed to detect long-term trends in kelp biomass as well as to determine how the roles of various environmental controls change over time.

In the present study, we introduce a new kelp canopy biomass data set possessing unprecedented spatial and temporal resolution and extent that was created using multispectral imagery from the Landsat 5 Thematic Mapper (TM) sensor. These observations enabled the assessment of giant-kelp canopy biomass at $30 \mathrm{~m}$ resolution across the entire Santa Barbara Channel every 1 to 2 mo for $25 \mathrm{yr}$ (1984 to 2009). We compared these novel observations of giant-kelp forests with oceanographic and climate observations to assess resource- and disturbance-driven controls on giant-kelp biomass at multiple spatial and temporal scales. Our objectives were to determine (1) the relative importance of nutrients and wave disturbance in driving both seasonal and interannual cycles of regional kelp biomass in the Santa Barbara Channel and (2) how the roles of these forcing processes vary spatially within the channel. We hypothesized that the 
negative effects of wave disturbance and nutrient limitation on giant-kelp biomass vary greatly in space and time due to the highly dynamic environmental conditions of the Santa Barbara Channel. We showed that kelp biomass was significantly negatively related to wave heights and sea surface temperatures (SST; a proxy for nutrient levels) at seasonal timescales. Interannual relationships were more complex as kelp biomass lagged wave heights, SST, and the North Pacific Gyre Oscillation (NPGO) climate index by 3 yr. We also demonstrated that these dependencies varied between distinct subregions within the Santa Barbara Channel.

\section{MATERIALS AND METHODS}

Study site. We tracked giant-kelp canopy biomass across the entire Santa Barbara Channel from 1984 to 2009. The study area included the coastline from Pismo Beach, CA to Oxnard, CA and each of the northern Channel Islands (Fig. 1). Giant kelp in this region is found primarily on shallow rocky reefs that are distributed in patches. The light-attenuation properties of the waters in the channel limit giant kelp to depths $<30 \mathrm{~m}$.

The Santa Barbara Channel experiences pronounced seasonal cycles in SST, nutrient conditions, and wave energy (Harms \& Winant 1998, Otero \& Siegel 2004).

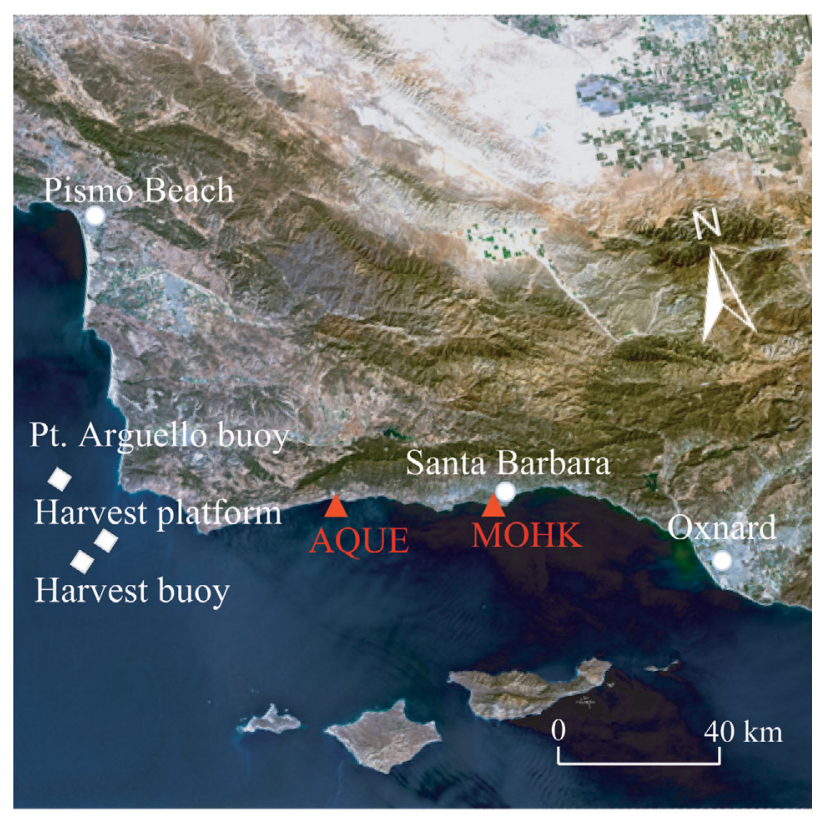

Fig. 1. Landsat 5 Thematic Mapper image displaying study area; Point Arguello, Harvest, and Harvest platform buoys; and Long Term Ecological Research (LTER) diver transects at the Arroyo Quemado (AQUE) and Mohawk (MOHK) kelp forests
During the winter, large storms in the North Pacific create large northwesterly swells ( $>4 \mathrm{~m}$ ) that enter the Santa Barbara Channel. Wave energy from these storms is a major source of giant-kelp mortality in the region (Reed et al. 2008). Nutrient levels are relatively high ( $3 \mu \mathrm{mol} \mathrm{l}^{-1}$ nitrate, Fram et al. 2008) in the winter as a deepening of the mixed layer entrains nutrients into surface waters (McPhee-Shaw et al. 2007). SST and nutrients (specifically nitrate and nitrite) are inversely correlated in the Santa Barbara Channel $\left(\mathrm{r}^{2}=\right.$ 0.87, Fram et al. 2008) and elsewhere in southern California. Studies done to date indicate that the growth of giant kelp in southern California is more commonly limited by low nutrients than by high SST (Clendenning \& Sargent 1971, North \& Zimmerman 1984).

Spring represents a period of transition in surface wave conditions as the frequency of large northwesterly wave events decreases, giving way to smaller southerly swells (2 to $3 \mathrm{~m}$ ) that are characteristic of summer months (Adams et al. 2008). Nitrate levels in the nearshore regions generally reach maximums

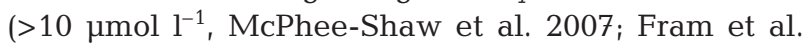
2008) during spring months due to coastal upwelling. During the summer and fall, vertical stratification increases, creating warmer temperatures and lower nitrate levels $\left(<1 \mu \mathrm{mol} \mathrm{l^{-1 }}\right.$, Fram et al. 2008). Less intense southerly swells are common in the summer months and can affect exposed south-facing coastlines.

The seasonal cycles in resource availability and physical disturbance are super-imposed on longer period cycles driven by El Niño-Southern Oscillation, Pacific Decadal Oscillation (PDO), and NPGO events. These lower-frequency climate cycles alter seawater temperatures, nutrient levels, and storm patterns, and can have dramatic effects on kelp populations (Dayton et al. 1999, Edwards 2004).

The Santa Barbara Channel also experiences a great deal of spatial variability in oceanographic conditions. The region is located at the convergence of the equatorward-flowing California Current and the recirculating Southern California Eddy and Inshore Countercurrent (Hickey 1979). Strong upwelling north of Point Conception creates cool, nutrient-rich conditions throughout most of the year, while regions in the eastern portion of the channel experience warmer, more nutrient-limited conditions during summer months (Otero \& Siegel 2004). While there is spatial variability in the SST of the Santa Barbara Channel, the vast majority of the region's temporal variability is homogeneous across the entire channel (Otero \& Siegel 2004, see 'Materials and methods-regional physical and climate data sets').

Even more dramatic is the spatial variability in wave exposure. Again, Point Conception represents a natural boundary: the coastline north of Point Conception is 
exposed to both powerful winter northwest swells as well as weaker summer southern swells while the coastline south of Point Conception is sheltered from northern swells by Point Conception and from southern swells by the Channel Islands (O'Reilly \& Guza 1993). The Channel Islands themselves present a myriad of exposures, but in general the north sides of the islands are exposed to northwest swells and sheltered from southern swells, while the opposite is true for the south-facing sides of the islands. Note that while these descriptions depict wave exposure in general, the precise spatial distribution of wave energy along the coast of our study area depends on the specific direction of a given swell (Adams et al. 2008). As with SST and nutrients, large, long-period swells affect the entire channel, but to varying degrees due to the large amount of spatial variability in wave exposure. Clearly, subtidal ecosystems of the Santa Barbara Channel such as giant kelp forests experience physical conditions that vary substantially in space and time.

Satellite estimation of giant-kelp canopy biomass. Giant kelp forms a dense floating canopy at the sea surface that is distinctive when viewed from above. In our study area, giant kelp is the only canopy-forming macrophyte in water depths from 5 to $30 \mathrm{~m}$. This greatly simplifies its quantification from satellite imagery. The spectral signature of a giant-kelp canopy is similar to that of photosynthetically active terrestrial vegetation, namely a high near-infrared and significantly lower visible reflectance (Jensen et al. 1980, Cavanaugh et al. 2010). Water absorbs almost all incoming near-infrared energy so kelp canopy is easily differentiated using its near-infrared reflectance signal.

The Landsat 5 TM sensor has acquired $30 \mathrm{~m}$ spatial resolution multispectral imagery nearly continuously from 1984 to the present on a $16 \mathrm{~d}$ repeat cycle (Markham et al. 2004). TM obtains data in 7 spectral bands: blue (450 to $520 \mathrm{~nm}$ ), green (520 to $600 \mathrm{~nm}$ ), red (630 to $690 \mathrm{~nm})$, near-infrared (760 to $900 \mathrm{~nm})$, shortwave infrared (1500 to 1750 and 2080 to $2350 \mathrm{~nm}$ ), and longwave (thermal) infrared (10400 to $12500 \mathrm{~nm}$ ) (http://landsat.gsfc.nasa.gov/about/tm.html). TM data is stored as 8-bit encoded radiance, with 256 possible 'brightness values' representing the range of radiance for each band. The kelp near-infrared (Band 4) radiance signal, while elevated compared to that of water, spans only the lowest $\sim 40$ brightness values detectable by TM. Each Landsat scene covers an area $170 \times 180 \mathrm{~km}$; the scene we used for the present study included the entire study area described above ('Study site') (Fig. 1). During preprocessing, Landsat images were geometrically corrected using ground control points and a digital elevation model to achieve a scene-to-scene registration accuracy $<7.3 \mathrm{~m}$ (Lee et al. 2004). We selected 209 relatively cloud-free images that provided us with coverage of the study area approximately every 2 mo from April 1984 to September 2009 (http://glovis.usgs. gov/).

We developed an automated classification and quantification process in order to consistently and efficiently transform the 209 TM images into maps of kelp canopy biomass. First, a single orthorectified TM image was atmospherically corrected to apparent surface reflectance using an atmospheric transmission model (MODTRAN4; Berk et al. 1998). We used this corrected image as a reference and standardized the radiometric signals from all other images to this reference using 50 targets that were assumed to be spectrally stable across the time series (i.e. airport runways, highways, sand dunes, lakes; Furby \& Campbell 2001, Baugh \& Groeneveld 2008). Outliers were manually removed to reduce the effects of temporal changes in target reflectance. This 'target matching' procedure accounted for all atmospheric, sensor, and processing differences between the scenes and created a timeseries of standardized TM imagery.

We estimated kelp canopy abundance from the calibrated TM reflectance data using multiple endmember spectral mixture analysis (MESMA). Spectral mixture analysis models the fractional cover of 2 or more 'endmembers' within a pixel. Each endmember represents a pure cover type, and endmembers are assumed to combine linearly (Adams et al. 1993). Standard spectral mixture analysis uses a uniform set of endmembers for the entire image. One challenge in the near-shore marine zone is that the 'water' reflectance is influenced by e.g. sun glint, breaking surface waves, phytoplankton blooms, dissolved organic matter, and sediment runoff. Since water reflectance is highly variable in space and time, a single water endmember cannot be used (Fig. 2A).

Roberts et al. (1998) developed MESMA to allow endmembers to vary on a per-pixel basis. By selecting from multiple endmembers for 1 or more cover types, MESMA can better capture the spectral variability of the cover type within an image and through time. MESMA has been extensively used for mapping terrestrial vegetation, including aridland vegetation (Okin et al. 2001), shrublands (Dennison \& Roberts 2003a), forests (Youngentob et al. 2011), and salt marsh (Li et al. 2005).

We modeled pixel reflectance as the linear mixture of reflectance of 2 endmembers: kelp and water. Thirty water endmembers were selected from non-kelpcovered areas within each TM scene using the endmember selection technique described by Dennison \& Roberts (2003b). A single kelp endmember was selected by extracting kelp-covered pixel spectra from each image and finding the single spectrum that fit the entire library of kelp spectra with the lowest root mean 

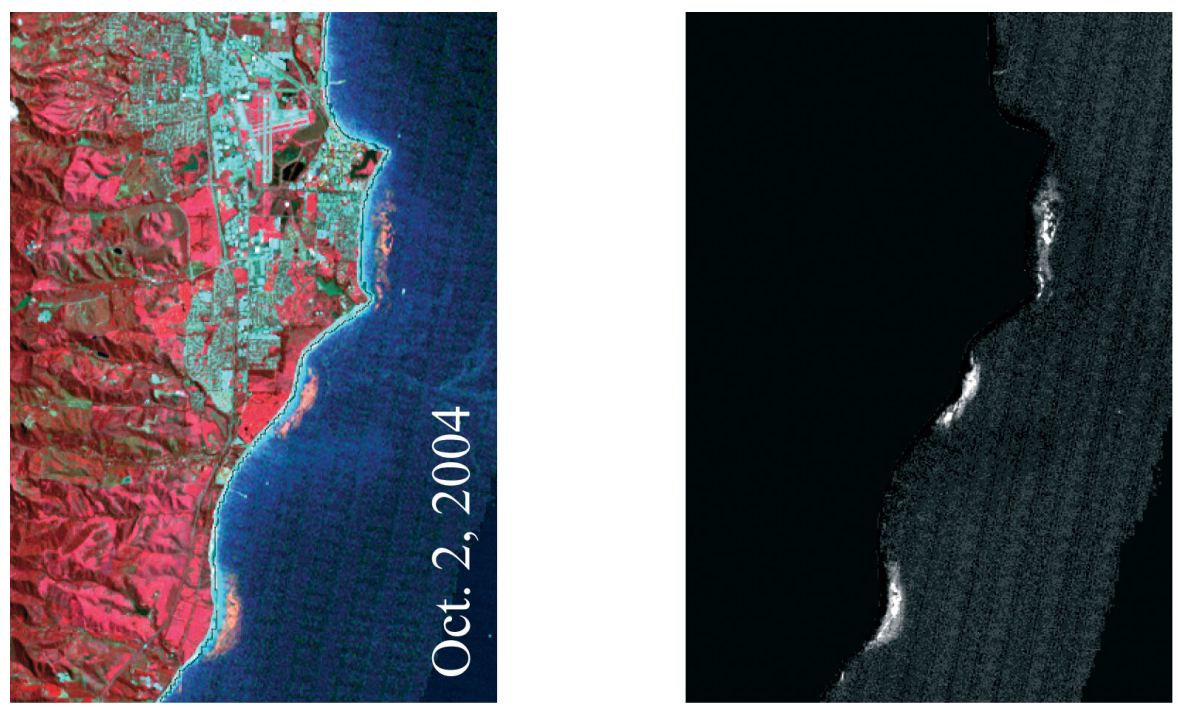

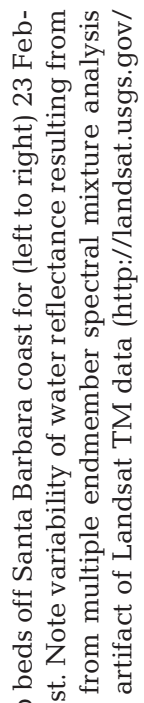

오윰

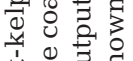
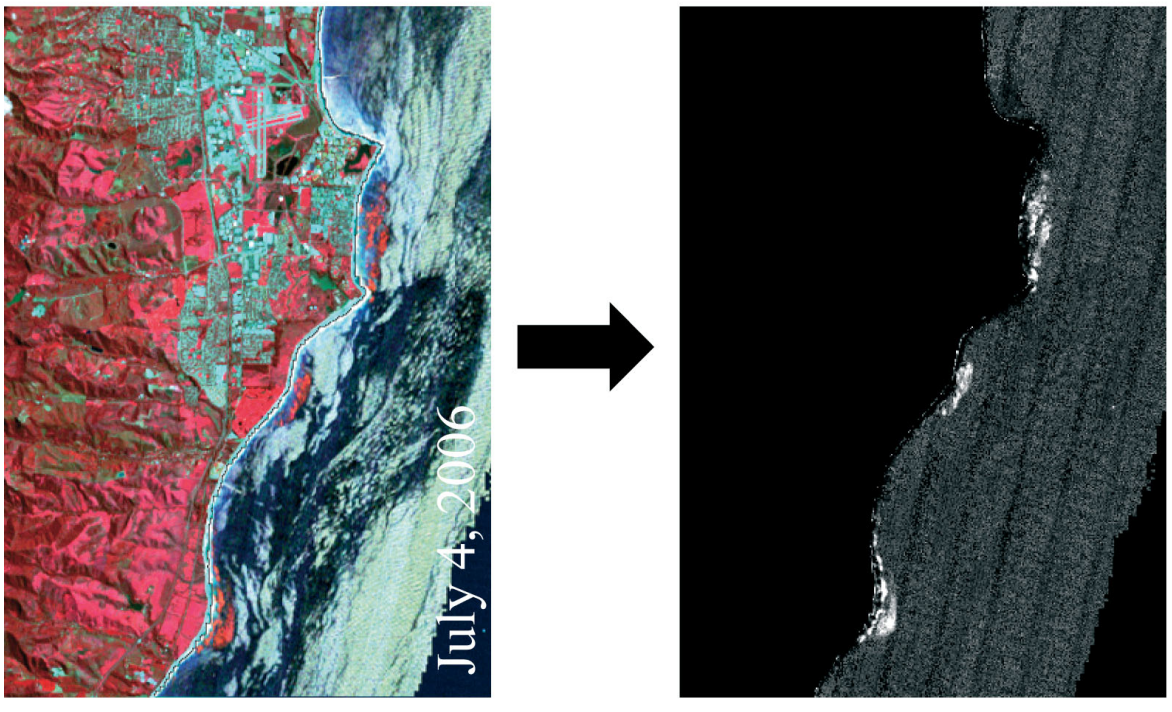

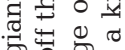

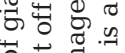

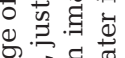

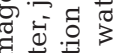

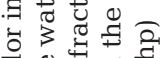

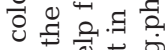

थ.

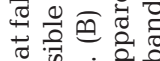

告 勿

주 \&

齿。

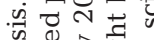

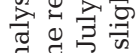

वृ

등 Ð

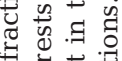

옹 兽泀泀
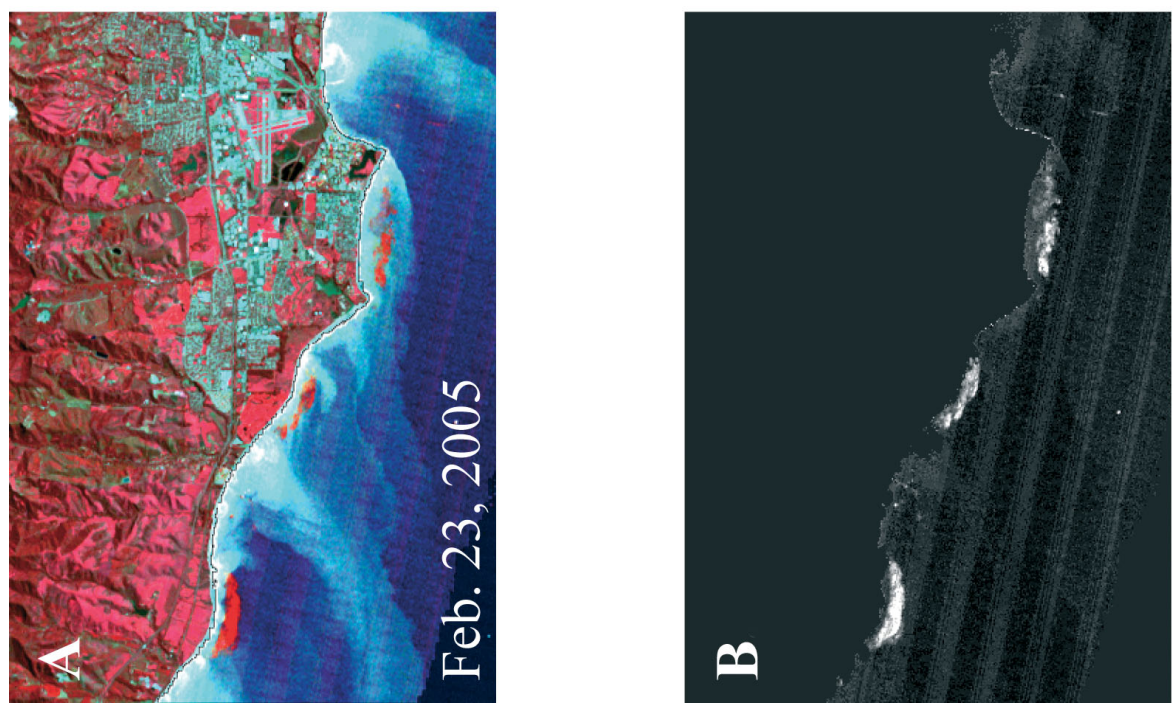

모웡

軎范

ए ن.

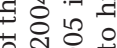

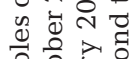

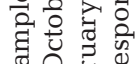

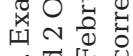

तु वृ

$\checkmark-N$

월

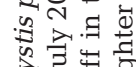

겅

ช

过范焉

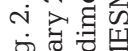

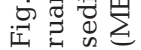


square error (RMSE) (Dennison \& Roberts 2003b). The pixels in each TM image were then modeled as a 2endmember mixture of kelp and each of the 30 water endmembers. The final model (out of 30) chosen for each pixel was the model that minimized RMSE when fit to the spectrum of that pixel. The result of this process was a measure of the relative fraction of each pixel that was covered by kelp canopy (Fig. 2B). We used a kelp fraction minimum threshold of 0.13 to automate the identification of 'kelp-covered' pixels. The multiple endmember process successfully delineated kelp canopy extent under a variety of conditions. Fig. 2 provides examples of how our technique retrieved kelp fractions from images under optimal conditions (2 October 2004) and for scenes that were contaminated by large amounts of sediment runoff (23 February 2005) and high levels of sun glint (4 July 2006).

The retrieved kelp fractions were then compared to giant-kelp canopy biomass observations that were collected by divers at permanent plots maintained by the Santa Barbara Coastal Long Term Ecological Research (SBC LTER) project at the Arroyo Quemado and Mohawk kelp forests (Fig. 1). The data and the methods used to measure giant-kelp canopy biomass from diver surveys are described in detail in Rassweiler et al. (2008). Briefly, divers measured the length of all fronds along 5 transects $(40 \times 1 \mathrm{~m})$ within a plot $(40 \times 40 \mathrm{~m})$ and converted these lengths to biomass using validated length-to-weight regressions. Each plot was overlapped by four $30 \mathrm{~m}$ TM pixels. For each TM image, we compared the mean kelp fraction of these pixels to the diver-measured canopy biomass of each plot with a model II reduced major axis linear regression (Legendre \& Legendre 1998) because both variables contain error.

Regional physical and climate data sets. Pearson correlation coefficients between the satellite-derived time series of kelp canopy biomass and physical and climate data that represented first-order controls of growth (nutrients) and disturbance (waves) were calculated on both seasonal and interannual timescales. Kelp canopy biomass was $\log _{10}$-transformed to meet assumptions of normality. SST was used as a proxy for ambient nitrate concentrations to investigate the effect of nutrient availability on changes in canopy biomass. Hourly SST measurements were collected from the National Data Buoy Center's Point Arguello buoy for the period 1984 to 2009 (Fig. 1). Otero \& Siegel (2004) performed temporal principal components analysis on $4 \mathrm{yr}$ (October 1997 to June 2001) of satellite-derived SST within our study area and found that $91 \%$ of the temporal variance was explained by the first mode of variability, which was positively correlated with all parts of the study area. Hence, a single point measurement of SST should be a reliable indicator of the regional temporal variability in SST and, by extension, nutrient concentration.
Significant wave height observations, the mean height of the one-third largest waves over a given period, were acquired from the National Data Buoy Center's Harvest buoy and Harvest platform sites (Fig. 1). The Harvest platform measured significant wave height every $3 \mathrm{~h}$ from January 1987 to April 1999 and the Harvest buoy has collected data twice per hour from March 1998 to the present. We combined these data sets to create a single time series of daily mean significant wave height from 1987 to 2009, using the Harvest buoy data when both the buoy and platform were operational. Overlapping data from the 2 were nearly identical (regression slope $=0.96$, bias $=0.18, \mathrm{r}^{2}=0.97$ ). Both the Harvest buoy and Harvest platform were located $\sim 30 \mathrm{~km}$ west of the Santa Barbara Channel in offshore locations exposed to long-period northwest and south swells. Giant kelp is predominantly affected by large wave events and powerful, long-period swell $(>12 \mathrm{~s})$ is more important than short-period sea in causing kelp mortality (Utter \& Denny 1996). Since longperiod swell affects the entire channel, we accepted a point measurement as a valid characterization of the regional wave environment with the understanding that there would be significant spatial variability in wave heights for a given swell measured by the Harvest buoys. Currently there is no spatially explicit data set of nearshore wave heights that matches the spatial resolution and temporal extent of our kelp data. Note that operational swell wave models for the Southern California Bight are parameterized using the same Harvest buoy data we used in the present study (see http://cdip.ucsd.edu).

The Harvest buoy also collects data on wave direction as well as height and period. For the period that the Harvest buoy was operational (1998 to present), seasonal histograms of wave direction were calculated for all swell events with periods $\geq 12 \mathrm{~s}$ in order to capture the seasonal variability in swell direction. Directional wave data were used to identify sections of the coast that represented strong gradients in wave exposure.

The kelp time series was also compared to the indices of 3 climate cycles known to affect oceanographic conditions in the Santa Barbara Channel: the Southern Oscillation Index or SOI (www.cpc.noaa.gov/ data/indices/soi), PDO (http://jisao.washington.edu/ pdo/), and NPGO (www.o3d.org/npgo/data/NPGO.txt). By convention, positive anomalies in the PDO represent warmer, nutrient-poor conditions in the Santa Barbara Channel, while positive anomalies in the SOI and NPGO represent increased upwelling, nutrient, and chlorophyll a levels. We reversed the sign of the SOI and NPGO for all figures and analyses so that positive deviations in all climate indices plotted represent warmer, nutrient-poor conditions. 
Subregional dynamics. Spatial heterogeneity in the responses of local kelp populations to regional physical forcings cannot be captured by a regional comparison. Clustering analysis was used to gain insight into how the relationships between physical variables and kelp canopy dynamics varied in space. First, the coastline was divided into $1 \mathrm{~km}$ segments and each pixel of kelp canopy was assigned to the closest coastline segment. Segments where kelp did not appear in at least $25 \%$ of the images were removed from analysis. Because the amount of kelp in each coastline segment varied, the $1 \mathrm{~km}$ segment biomass values were standardized as the proportion of that segment's maximum biomass over the entire time series. The data were then normalized across segments by subtracting the regional mean and dividing by the regional standard deviation of each date. Each segment's degree of wave exposure was calculated using an exposure index based on Baardseth (1970). A circle with a radius of $100 \mathrm{~km}$ was placed at the center of each $1 \mathrm{~km}$ section of coastline and divided into 40 sectors, each of which had an angle of $9^{\circ}$. Sectors were given a score of 0 if they intersected land and 1 if they were free of land. The exposure index is the sum of sector scores; 0 represents complete shelter and 40 represents maximum exposure.

$k$-means clustering was used to identify subregions with similar temporal dynamics (e.g. Huth 1996). The $k$-means classification is an unsupervised classification technique that requires the number of clusters to be specified beforehand. The data were clustered using 2 to 7 clusters to examine the robustness of the results. The kelp canopy biomass of each subregion was then $\log _{10}$-normalized and compared to the physical and climate data described in 'Regional physical and climate data sets' above.

\section{RESULTS}

\section{Landsat estimation of kelp canopy biomass}

A strong positive linear relationship was found between the Landsat-derived kelp fraction index and giant-kelp canopy biomass $\left(r^{2}=0.64, p \ll 0.001, \mathrm{df}=94\right.$; Fig. 3). We restricted our comparisons to canopy biomass rather than total biomass because near-infrared remote sensing only detects floating kelp. Generally, canopy biomass is highly correlated to total biomass $\left(r^{2}=0.92\right.$; D. C. Reed unpubl. data); however, the relationship between TM kelp fraction and canopy biomass was stronger than between kelp fraction and total biomass $\left(\mathrm{r}^{2}=0.49, \mathrm{p} \ll 0.001, \mathrm{df}=94\right)$. This discrepancy was driven by a few data points where the ratio of canopy to total biomass was unusually low. Neither tidal nor current fluctuations had any effect on

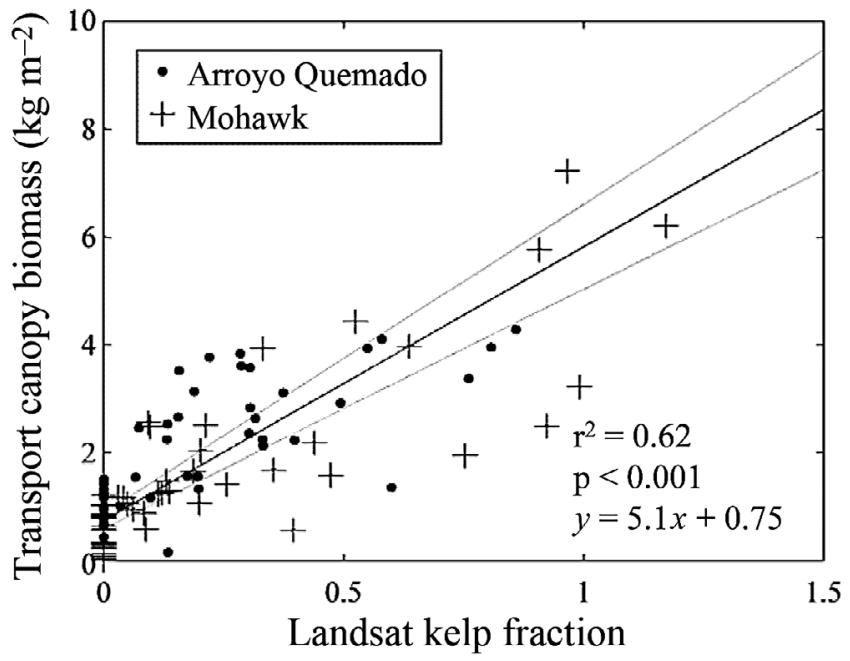

Fig. 3. Macrocystis pyrifera. Validation of Landsat satellite biomass estimates. Model II linear regression between Landsat kelp fractions and diver-measured canopy biomass $\left(\mathrm{kg} \mathrm{m}^{-2}\right)$ measurements for the Arroyo Quemado and Mohawk $(n=96)$ transects. The gray lines represent $95 \%$ confidence intervals for the relationship

the kelp fraction-canopy biomass relationship $(\mathrm{p}=0.65$ and 0.25 when the residuals of the fraction-biomass relationship were compared to local tides and currents for the time of Landsat data collection, respectively). This result agrees with our previous work (Cavanaugh et al. 2010) showing that the relatively weak tidal fluctuations and current speeds in this area do not affect remote sensing estimates of kelp biomass as they do in other locations (e.g. Britton-Simmons et al. 2008).

\section{Regional dynamics}

The regionally averaged giant-kelp canopy biomass calculated using the relationship between satellitederived kelp fraction and diver-measured canopy biomass is shown in Fig. 4A. The long-term (1984 to 2009) mean regional giant-kelp canopy biomass was $46000 \mathrm{t}$ (wet), but there was an extremely high amount of variability about this mean, as evidenced by a temporal coefficient of variation calculated over all 209 images of $91 \%$. Changes in regional kelp biomass were rapid, and order of magnitude increases and decreases in regional mean biomass routinely occurred over a span of $<4$ mo. Most years displayed a seasonal cycle, with biomass minimums occurring in the winter followed by rapid growth in the spring and early summer leading to maximums in late summer or early fall; however, the amplitude and timing of this cycle varied substantially. This seasonal cycle was superimposed on a cycle with a 12 to 13 yr period. In this longer cycle relatively low 


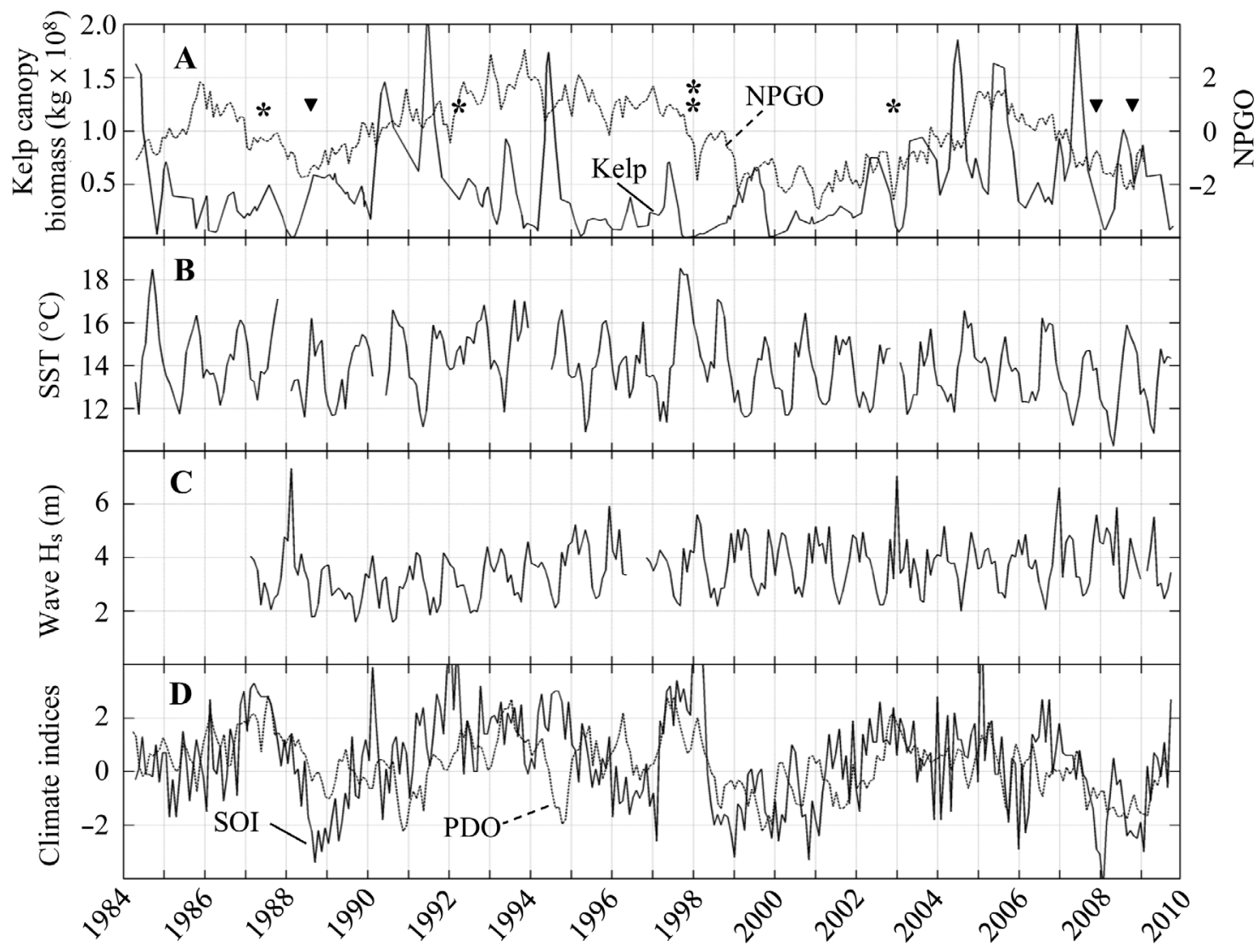

Fig. 4. Macrocystis pyrifera. (A) Santa Barbara Channel regional mean time series of giant-kelp canopy biomass and North Pacific Gyre Oscillation (NPGO) anomalies. Kelp canopy biomass was summed across the entire study area shown in Fig. 1. One-month running mean of (B) sea surface temperature (SST) and (C) significant wave height $\left(\mathrm{H}_{\mathrm{s}}\right)$ from Point Arguello buoy, Harvest platform, and Harvest buoy data. (D) Monthly Southern Oscillation Index (SOI) and Pacific Decadal Oscillation (PDO) anomalies. Asterisks in (A) represent strong El Niño events, with the 2 asterisks in 1997-1998 identifying the strongest El Niño on record, while $\boldsymbol{\nabla}$ represent strong La Niña events (as classified by Smith \& Sardeshmukh 2000)

periods of canopy biomass in 1984-1990 and 19942003 were separated by high biomass periods in $1990-$ 1995 and 2003-2009. The length of this cycle matches the 11 to $13 \mathrm{yr}$ period of the NPGO (our Fig. $4 \mathrm{~A}_{i} \mathrm{Di}$ Lorenzo et al. 2008). We plotted the kelp and NPGO time series together in Fig. 4A to emphasize this match in periods. There were no long-term trends in the regional canopy-biomass time series.

Both SST and wave height displayed the pronounced seasonal cycles characteristic of this region (Fig. 4B,C). SST typically reached its annual minimum between February and March and its maximum between August and October, and we can infer that nitrate showed the opposite pattern. Significant wave height maxima occurred in the winter months, corresponding with the timing of increased storm activity in the North Pacific. Between 1987 and 2009, the annual maximum winter (December to February) wave height averaged $4.9 \mathrm{~m}$ while the annual maximum summer (June to August) wave height averaged 3.26 m. During our study period, annual mean significant wave heights increased significantly at the pace of $0.02 \mathrm{~m} \mathrm{yr}^{-1}\left(F_{1,22}=25.9, \mathrm{p}<\right.$ 0.001 ). This positive trend in wave height agrees with other observations of increasing wave heights in the Northeast Pacific over the last $60 \mathrm{yr}$ (Bromirski et al. 2003, Ruggiero et al. 2010).

The oscillations of the 3 climate cycles ranged from 3-7 yr (SOI) to $11-13 \mathrm{yr}$ (NPGO) to $20-30 \mathrm{yr}$ (PDO) (Fig. 4A,D). All climate indices experienced both positive and negative extremes during our study period. The 1990s saw a number of positive El Niño anomalies and the 1997-1998 El Niño was one of the strongest ever recorded. La Niña conditions were present in 19981999, 2001, and 2008. The NPGO cycled fairly consistently with positive (nutrient-poor) anomalies in the early 1990s and mid-2000s, separated by negative anomalies in the early 2000s. The PDO displayed mostly positive anomalies from the beginning of the time series until the early to mid-2000s, when negative anomalies became more prevalent; this change may represent a shift of the 
PDO from the warm phase that began in the late 1970s (Mantua et al. 1997, Peterson \& Schwing 2003). All climate indices were positively correlated with SST (and hence negatively correlated with nitrate) (Table 1). The NPGO was weakly negatively correlated with higher wave heights; there was no significant relationship between either SOI or PDO and waves.

\section{Seasonal relationships to physical and climate variables}

We examined the relationships between physical and climate variables and monthly variability in kelp biomass by calculating Pearson correlation coefficients between $\log _{10}$-transformed regional kelp-canopy biomass and each of the physical and climate variables. Univariate correlation analyses indicated that there were significant but weak negative relationships between kelp canopy biomass and both SST and wave height on monthly timescales (Table 1). The failure of SST and wave height to explain much variation in kelp canopy biomass at this scale is not surprising given the high level of month-to-month variability in the kelp time series as well as the large spatial scale over which regional kelp biomass was evaluated. The PDO was the only climate index with a significant correlation to kelp biomass; the relationship was negative but again weak. While the SOI index was not significantly correlated with kelp biomass, strong El Niño events in the winters of 1997-1998 and 2002-2003 corresponded

Table 1. Macrocystis pyrifera. Pearson correlation coefficients for regional giant kelp and climatic forcing data calculated on (A) monthly and (B) annual timescales. For the monthly comparisons, $\log _{10}$-normalized regional kelp-canopy biomass from each image date was correlated to the mean of the physical and climate data from $30 \mathrm{~d}$ before the image date. For the annual comparisons, the annual mean of kelp was compared to the annual means of sea surface temperature (SST), Southern Oscillation Index (SOI), Pacific Decadal Oscillation (PDO), and North Pacific Gyre Oscillation (NPGO) and the annual maximum of wave height. Bold values are significant at the $99 \%$ confidence level

\begin{tabular}{|lrrrrr|}
\hline & $\log _{10}(k e l p)$ & NPGO & PDO & SOI & Waves \\
\hline (A) Monthly & & & & & \\
SST & $\mathbf{- 0 . 2 6}$ & $\mathbf{0 . 2 3}$ & 0.08 & $\mathbf{0 . 1 8}$ & $\mathbf{- 0 . 3 5}$ \\
Waves & $\mathbf{- 0 . 3 0}$ & $\mathbf{- 0 . 2 4}$ & 0.04 & 0.00 & \\
SOI & -0.09 & $\mathbf{0 . 3 2}$ & $\mathbf{0 . 4 4}$ & & \\
PDO & $\mathbf{- 0 . 2 2}$ & $\mathbf{0 . 4 1}$ & & & \\
NPGO & -0.01 & & & & \\
(B) Annual & & & & & \\
SST & -0.10 & $\mathbf{0 . 6 0}$ & $\mathbf{0 . 5 3}$ & $\mathbf{0 . 6 2}$ & -0.40 \\
Waves & -0.27 & -0.39 & 0.10 & -0.16 & \\
SOI & 0.16 & $\mathbf{0 . 6 0}$ & $\mathbf{0 . 6 0}$ & & \\
PDO & -0.25 & $\mathbf{0 . 5 4}$ & & & \\
NPGO & 0.08 & & & & \\
\hline
\end{tabular}

with massive regional kelp-canopy losses (regional kelp biomass dropped to almost zero). In addition, strong La Niña events in late 1988 and 2008 marked large increases in regional kelp biomass.

We further investigated the relationship between physical forcings and seasonal kelp variability by isolating winter canopy losses and spring recoveries and comparing them to our physical forcing variables. Winter loss was defined as the percent change in regional kelp-canopy biomass from the fall (August to November) maximum to the winter (December to March) minimum of each year; the specific time frame varied from year to year depending on the timing of kelp maximums and minimums. We compared the percent decrease in kelp biomass to the maximum wave height over the same time period and found a strong positive polynomial relationship between the 2 that appeared to saturate between wave heights of 6 to $7 \mathrm{~m}$ (Fig. 5A).
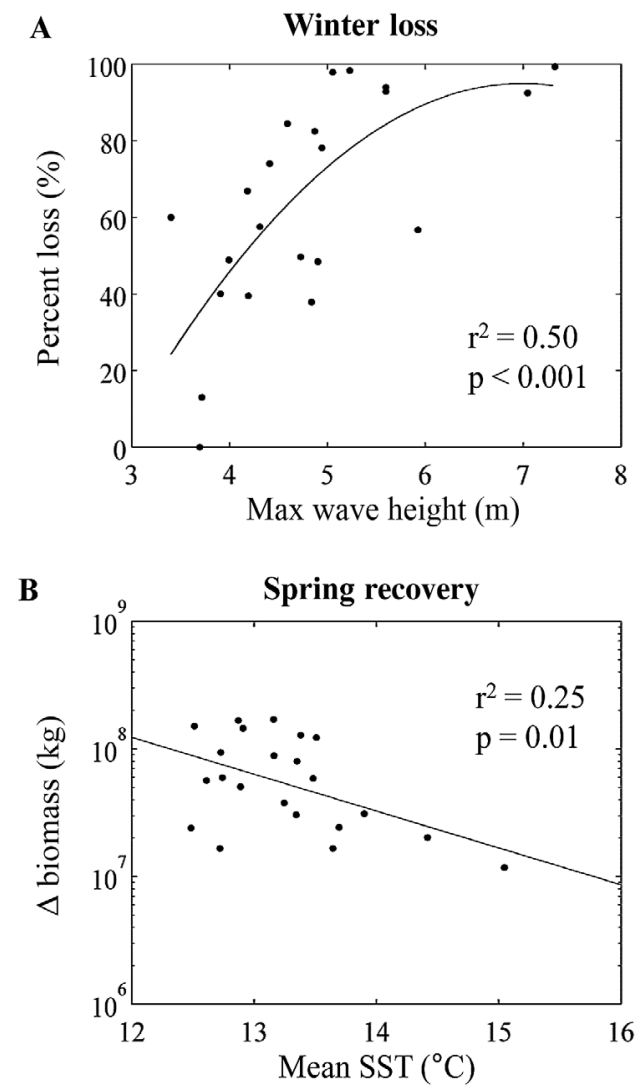

Fig. 5. Macrocystis pyrifera. Regression analysis between (A) winter kelp canopy biomass losses and maximum significant wave height and (B) spring-summer kelp canopy biomass recovery and mean sea surface temperature (SST). Winter losses were calculated as the percent change in kelp canopy biomass from the fall (September to November) maximum to the winter-spring (December to May) minimum. Recovery represents the $\log _{10}$ change in kelp canopy biomass from the winter-spring (December to May) minimum to the summer (June to August) maximum. Maximum wave height and mean SST for each year were calculated over the same periods 
Only the extreme wave events appeared to control regional kelp biomass; we did not find significant relationships between waves and kelp losses for other times of the year when waves were smaller. There was no significant relationship between winter canopy loss and nutrient levels as measured using SST $\left(\mathrm{r}^{2}=0.00\right.$, $\mathrm{p}=0.75$ ). Among the climate indices we found a weak but significant positive relationship between winter PDO and kelp loss $\left(\mathrm{r}^{2}=0.19, \mathrm{p}=0.03\right)$ and between winter SOI and kelp loss $\left(\mathrm{r}^{2}=0.16, \mathrm{p}=0.05\right)$ but no significant relationship between NPGO and kelp loss $\left(\mathrm{r}^{2}=0.05, \mathrm{p}=0.31\right)$. Winters with a positive SOI have been shown to produce stronger storms that take more southerly tracks across the North Pacific (Seymour 1998); wave events during some of these years may explain the positive relationship between the SOI and winter kelp loss.

A similar analysis was performed between the recovery of canopy biomass in spring and nutrient levels as approximated by SST. Spring recovery was defined as the increase in canopy biomass between the winter (December to March) minimum and the spring-summer (April to July) maximum of each year. Biomass increases were $\log _{10}$-transformed to meet assumptions of normality for the linear regression. There was a weaker (as compared to kelp loss vs. waves) but still significant negative linear relationship between spring recovery of regional kelp biomass and mean SST (Fig. 5B). There was no significant relationship between spring recovery and wave heights or any of the lower frequency climate indices.

\section{Interannual relationships between biomass and environmental variables}

To investigate regional drivers of interannual variability in kelp canopy biomass, we calculated the crosscorrelations between annual mean canopy biomass for the entire Santa Barbara Channel and the annual means of SST and the 3 climate indices, and annual maximums of significant wave height. Each of these correlations was investigated at time lags ranging from 0 to 6 yr. On interannual timescales, annual mean regional kelp-canopy biomass was not directly related (i.e. time lag $=0$ ) to any of the physical or climate variables (Table 1B). However, a lagged correlation analysis revealed strong significant relationships between kelp canopy biomass and SST, waves, and NPGO when these environmental variables were lagged 3 yr (Fig. 6); biomass was negatively related to SST $(\mathrm{r}=-0.48)$, positively related to wave height $(\mathrm{r}=$ $0.48)$, and negatively related to the NPGO index ( $\mathrm{r}=$ $-0.50)$. These lagged relationships are likely due to environmental controls of recruitment and juvenile growth (see 'Discussion'). There was no significant relationship between kelp canopy biomass and SOI or PDO for any time lag.

\section{Subregional dynamics}

The clustering analysis divided the Santa Barbara Channel into 4 subregions along wave exposure and nutrient gradients. The clustering results were robust
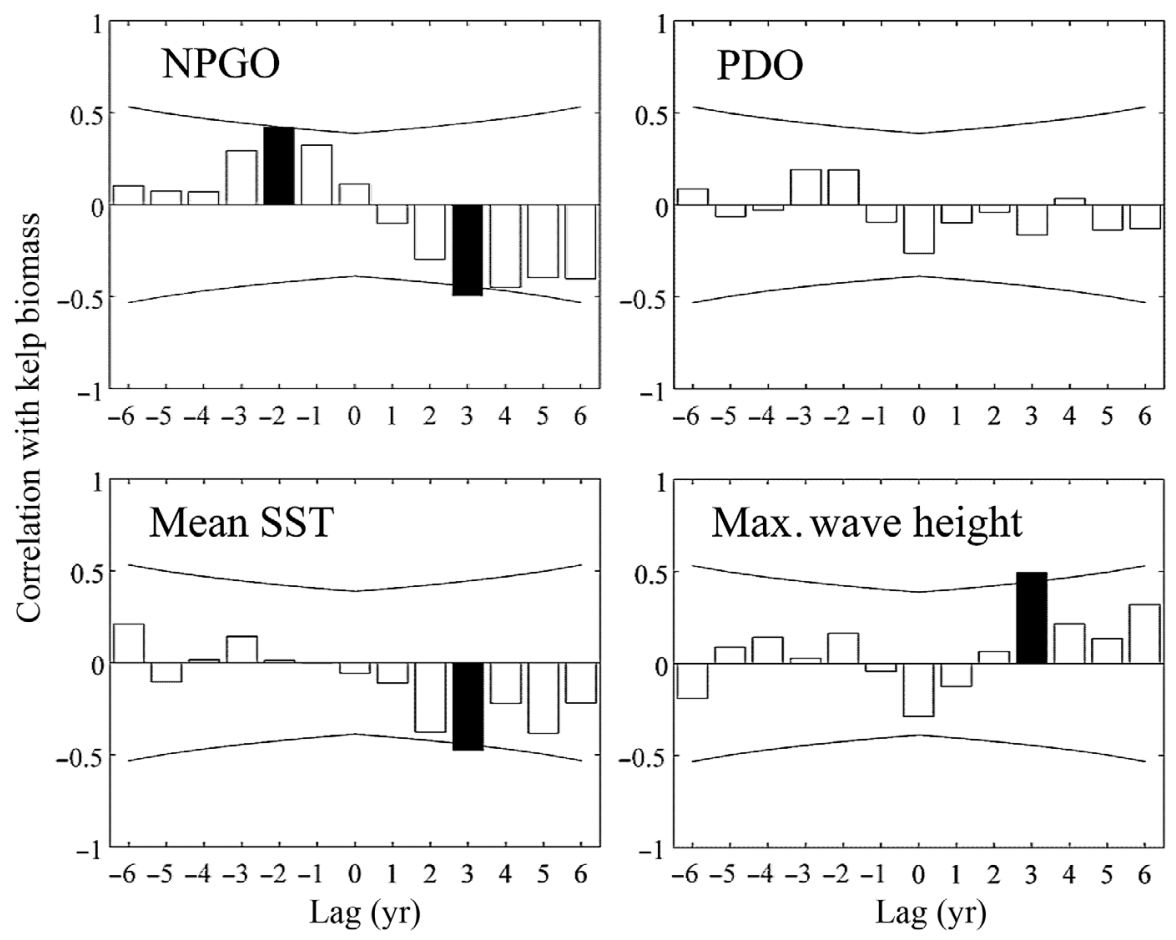

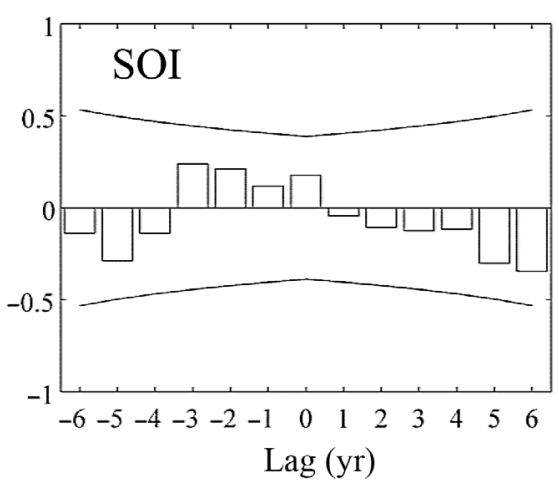

Fig. 6. Macrocystis pyrifera. Cross-correlation analysis (at lags of 0 to 6 yr) of climate indices and physical variables with annual mean kelp canopy biomass. Annual mean kelp biomass was compared to mean sea surface temperature (SST; lower left panel), Southern Oscillation Index (SOI; upper right panel), Pacific Decadal Oscillation (PDO; upper central panel), and North Pacific Gyre Oscillation (NPGO; upper left panel) and maximum wave height (lower right panel) for each year. Black bars are significant at the $95 \%$ level 
Fig. 7. Macrocystis pyrifera. Results from $k$-means cluster analysis $(\mathrm{N}=4$ clusters) on monthly canopy biomass data binned into $1 \mathrm{~km}$ sections of coastline. Subregions are labeled A to D in order of decreasing exposure. Histograms of significant wave height $\left(\mathrm{H}_{\mathrm{s}}\right)$ and direction for swells with periods $>12 \mathrm{~s}$ are provided for winter (December to February) and summer (June to August) from Harvest platform. Coastlines are colored to differentiate subregions and are not related to the color key for the wave histograms

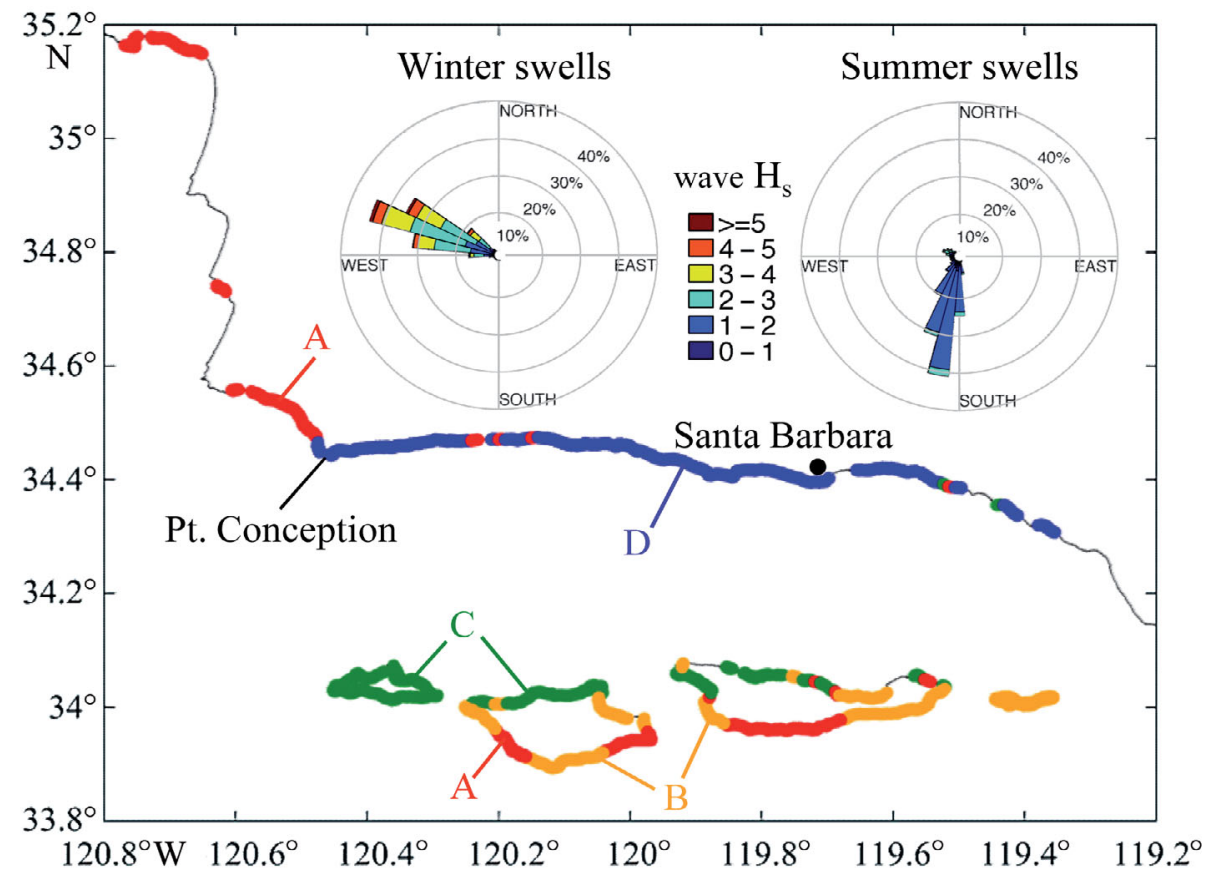

to varying the number of clusters used in the $k$-means algorithm: all solutions separated the mainland coastline at Point Conception and separated the north and south sides of the Channel Islands (Fig. 7). Increasing the number of clusters simply further separated these 4 'major' subregions into smaller groups. Bonferroniadjusted paired $t$-tests demonstrated that the mean exposures of the 2 'exposed' subregions (A and B) were not significantly different from each other, but each was significantly different from the 2 'sheltered' regions (C and $D)(p<0.01$, Table 2). Note that the exposure index measures potential exposure and does not take into account the direction of swells. Because the largest swells in the Santa Barbara Channel come from the northwest (Fig. 7), the index may overestimate the realized exposure of regions that are sheltered from northwest swells but exposed to swells from other directions (i.e. Subregion B).

Table 2. Macrocystis pyrifera. Mean exposure index and correlation to physical data for each subregion (A to D) identified in Fig. 7. Subregional kelp canopy biomass levels from each image date were $\log _{10}$-normalized and correlated to the mean of the physical and climate data from $30 \mathrm{~d}$ before the image date. Bold values are significant at the $99 \%$ level. SST: sea surface temperature

\begin{tabular}{|lllcc|}
\hline & \multicolumn{4}{c|}{ Subregion } \\
& $\mathrm{A}$ & $\mathrm{B}$ & $\mathrm{C}$ & $\mathrm{D}$ \\
\hline Exposure index & 11.8 & 11.6 & 6.2 & 4.5 \\
SST correlation & -0.08 & -0.17 & $\mathbf{- 0 . 3 4}$ & $\mathbf{- 0 . 3 1}$ \\
Wave correlation & $\mathbf{- 0 . 4 8}$ & $\mathbf{- 0 . 2 9}$ & -0.13 & 0.01 \\
\hline
\end{tabular}

Temporal dynamics of the 4 subregions were relatively similar (mean pairwise $r=0.61$, Fig. 8); however, upon closer inspection it was possible to identify differences that tracked wave exposure. Kelp-canopy biomass dynamics of the exposed subregions were significantly negatively correlated to maximum wave heights, but not SST, while the dynamics of sheltered subregions were negatively correlated to SST, but not with wave heights (Table 2). In addition, the strength of seasonal cycles increased with increasing exposure (Fig. 9). As the strength of the seasonal cycle decreased with decreasing wave exposure, the strength of the longer 12 to 13 yr period cycle increased, suggesting a closer connection between the NPGO and sheltered regions (Fig. 8). For example, the extended periods of low regional canopy biomass in 1984-1990 and 1994-2003 reflected a near-complete lack of recovery in the sheltered regions while the exposed regions maintained relatively high levels of biomass during these years.

\section{DISCUSSION}

\section{Remote sensing of kelp forests}

Our Landsat 5 TM data set represents the first highresolution, local- to regional-scale assessment of giantkelp canopy biomass on monthly-to-decadal timescales. This data set is itself a significant accomplishment as it provides a novel view into kelp-forest dynamics across a wide range of scales. Previous studies have demon- 


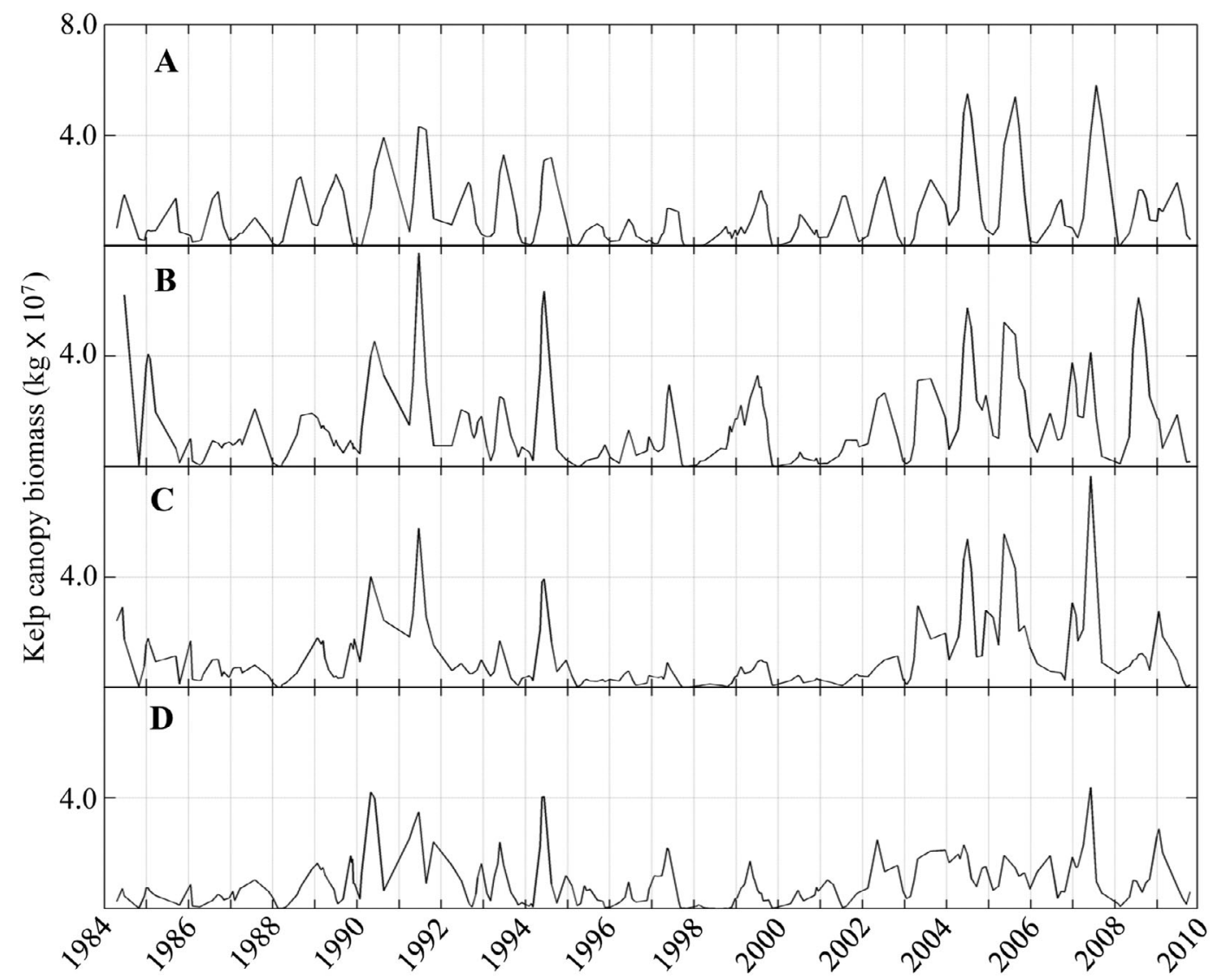

Fig. 8. Macrocystis pyrifera. Time series of total kelp canopy biomass for each subregion (A to D) identified in Fig. 7

strated the feasibility of measuring kelp canopy cover and biomass with aerial and satellite imagery (Jensen et al. 1980, Deysher 1993, Stekoll et al. 2006, Cavanaugh et al. 2010); however, these studies have not had the extended temporal coverage that is presented here. Parnell et al. (2010) examined annual-to-decadal variability in giant-kelp cover near San Diego using aerial surveys, but they used maximum annual canopy area and so did not measure seasonal variability. While Landsat provides unmatched temporal resolution and coverage, it has a coarser spatial resolution than the sensors used in some of these previous studies $(30 \mathrm{~m}$ with Landsat, as compared to $\sim 1 \mathrm{~m}$ in Stekoll et al. 2006 and $10 \mathrm{~m}$ in Cavanaugh et al. 2010). In addition, Landsat has a relatively low radiometric resolution, which limits its ability to differentiate small changes in reflectance between pixels. One consequence of the reduced spatial and radiometric resolution of Landsat is higher levels of uncertainty when comparing satellite data to transect-scale diver-measured biomass (the $\mathrm{r}^{2}$ between Landsat and diver-measured canopy biomass was 0.64 , compared to 0.77 for Cavanaugh et al. 2010 and 0.84 for Stekoll et al. 2006). Nevertheless, the Landsat-measured and diver-measured canopy biomass relationship was still strong and highly signifi- cant and provides a path for assessing regional satellite canopy biomass variations. As the availability of imagery with higher spatial and radiometric resolutions increases, more accurate remotely sensed time series of kelp biomass can be developed using techniques similar to the one we have presented here. However, not all species of kelp are amenable to remote sensing by this method, which relies on nearinfrared reflectance that is rapidly attenuated by water. Consequently, the usefulness of satellite imagery in studying the dynamics of marine vegetation is at present limited to species that produce a dense, floating canopy of an appropriate spatial scale.

\section{Regional dynamics}

We did not find a significant long-term trend in the 25 yr record of kelp canopy biomass of the Santa Barbara Channel. Long-term trends in giant kelp are difficult to identify because canopy biomass varies across orders of magnitude over short time periods. Large disturbance events (i.e. strong El Niño events) cause dramatic large-scale reductions in canopy biomass; however, recoveries can be almost as rapid (Figs. 4 \& 8). 

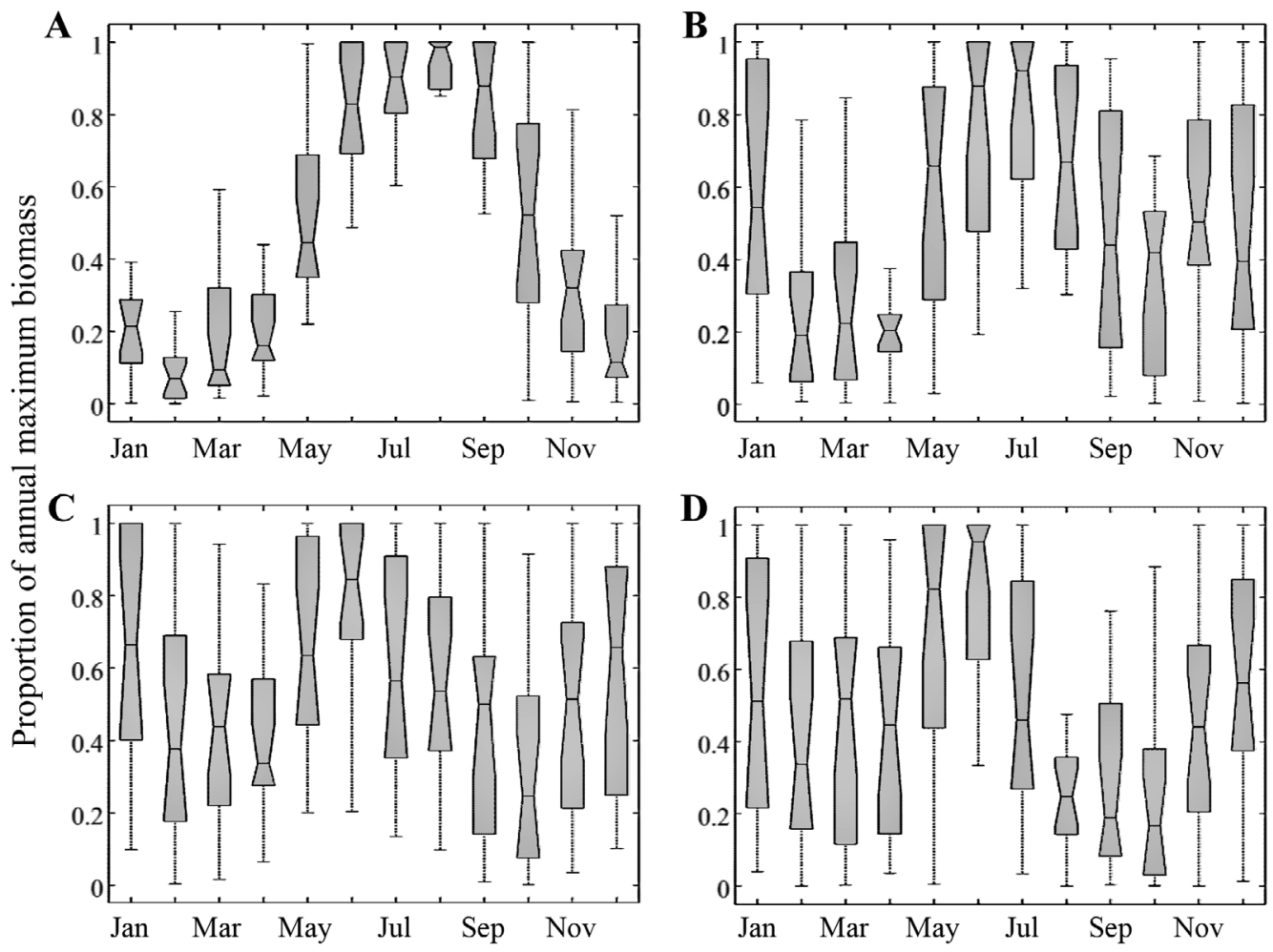

Fig. 9. Macrocystis pyrifera. Box-and-whisker plots of the seasonal cycle in canopy biomass for each subregion (A to D) identified in Fig. 7. For each year between 1984 and 2009, the proportion of that year's maximum biomass was calculated for each month. Boxes represent the lower quartile, median, and upper quartile of the proportion of annual maximum biomass, and whiskers extend to the lower and upper extremes of the data. Longer boxes represent months with higher variability in their relative canopy biomass levels. Boxes whose notches (not whiskers) do not overlap have significantly different medians at a $95 \%$ confidence level

There is an upper limit on the amount of kelp that the region can support that is based simply on the availability of suitable habitat. However, it seems difficult to identify a regional equilibrium for giant-kelp canopy due to its highly dynamic nature. If the global extent of kelp is changing, then it will likely be difficult to detect in regions such as the Santa Barbara Channel that are at the center of the giant kelp's hemispherical range. While we did not observe a long-term directional trend in kelp canopy biomass, we did find that regional-scale kelp biomass oscillated on cycles with periods of 1 and 12-13 yr. The annual cycles were driven by losses related to winter storm activity and, to a lesser extent, recovery linked to nutrient levels (Fig. 5). While physical storm-driven mortality was direct and immediate, the effect of nutrients on kelp growth were likely delayed and complicated by a number of other factors, including the availability of light and unoccupied hard substrate, and spore settlement and recruitment; hence, a weaker relationship was observed. While these winter losses and spring recoveries characterized the annual cycle in general, there was substantial variability in the amplitude and timing of these cycles among years.
Interannual relationships between kelp canopy biomass and physical drivers were less clear. Recovery of kelp populations can be extremely rapid. Thus annual means and maximums can be decoupled from the previous winter's wave disturbance. This may help explain why past studies using annual observations made in the summer or fall failed to find a relationship between waves and kelp population metrics (Tegner et al. 1996). The longer period cycles in kelp biomass corresponded to the NPGO, waves, and nutrient levels (as inferred from SST), but lagged these variables by 3 yr (Fig. 6). This 3 yr lag is somewhat counterintuitive in light of the rapid turnover of the fronds that create kelp canopies. We suspect that the lagged relationships are related to the recruitment and mortality of entire plants. While losses of fronds on extant plants occur continuously throughout the year, mortality of entire plants occurs more episodically and is related to large wave events ( $>1 \mathrm{~m}$ in Reed et al. 2008). Exceptionally large wave events can clear space and allow for dramatic spikes in recruitment (Graham et al. 1997). Previous work has shown that environmental conditions at the time of recruitment and juvenile growth of kelp cohorts can have long-lasting effects on 
population dynamics and community structure (Tegner et al. 1997, Dayton et al. 1999). For example, Tegner et al. (1997) compared succession after 2 large disturbances under contrasting oceanographic regimes and found that nutrient-rich conditions led to high densities and competitive dominance of giant kelp that lasted for the life of the cohort ( 5 yr). This result agrees with the lagged negative relationship we found between SST (and by extension, nutrients) and kelp canopy biomass. Together, large waves and high nutrient levels in a given year promote the recruitment and growth of a new cohort of giant-kelp plants (Fig. 10). This cohort matures over the next 2 to $3 \mathrm{yr}$, developing high levels of canopy biomass in the absence of severe storms. We found that severe storms with long-period wave events $>5.5 \mathrm{~m}$ occurred at an average frequency of 1 every 2 to $4 \mathrm{yr}$, thus allowing populations to expand their areal extents until the cycle is repeated or all available habitat is utilized.

Many studies have linked massive declines in kelp populations to severe El Niño conditions and have observed rapid recovery of kelp populations during nutrient-rich La Niña events (Dayton \& Tegner 1990, Dayton et al. 1992, 1999, Edwards 2004). In addition, Parnell et al. (2010) found that the response of kelp populations to El Niño events is modulated by lowfrequency changes in the PDO: the importance of nutrient control in the San Diego area increased after the PDO switched to a warm phase in the late 1970s. However, the relationship between kelp and the NPGO has largely been neglected. We observed that strong El Niño events in 1987, 1997, and 2003 coin-
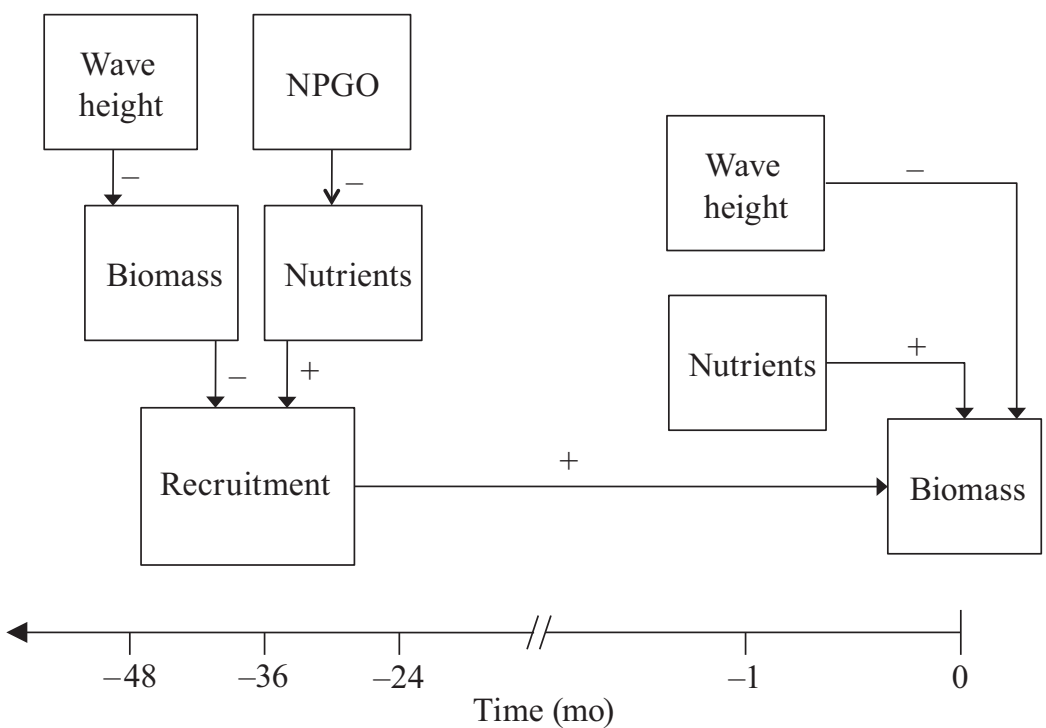

Fig. 10. Macrocystis pyrifera. Conceptual model of factors that influence regional giant-kelp canopy biomass. NPGO: North Pacific Gyre Oscillation. ' + ' and '-' represent positive and negative relationships between the variables inside the boxes cided with large regional mortality events (Fig. 4); however, the long (12 to $13 \mathrm{yr}$ ) period cycles in regional kelp biomass were better correlated with the NPGO, again at a 3 yr lag. The NPGO is driven by regional variations in wind-driven upwelling and horizontal advection and corresponds closely with correlates of ecosystem productivity such as nutrient levels and chlorophyll concentrations (Di Lorenzo et al. 2008). Therefore, the NPGO appears to influence decadal variations in kelp canopy biomass though large-scale, low-frequency changes in nutrient availability that in turn affect recruitment and growth of giant kelp.

While no long-term trends were evident in the kelp time series, we did see a statistically significant longterm increase in mean and maximum significant wave heights over our study period. Other studies have observed similar trends in the Eastern Pacific (Bromirski et al. 2003, Ruggiero et al. 2010), and many climate models predict that the frequency and possibly the intensity of large storms will continue to increase in this region (Easterling et al. 2000, Meehl et al. 2000, 2007). This has the potential to increase the effects of wave events on the coastlines of southern California, leading to higher annual winter losses. Reed et al. (2008) found that biomass at the start of the growth year (after winter storm disturbances) explained 63\% of the annual net primary productivity of giant kelp at 3 sites along the mainland shore of the Santa Barbara Channel. Therefore, increased winter-time wave losses would likely lead to decreased annual productivity by giant kelp in this region. These types of threats to the productivity of habitat structuring kelps are not restricted to our study area; Wernberg et al. (2010) demonstrated how increases in wave disturbance and ocean temperatures can act synergistically to reduce the resilience of populations of the subsurface canopy-forming kelp Ecklonia radiata in Australia. In addition, the implications of increased levels of physical disturbance span trophic levels as repeated kelp loss due to waves has been linked to lower diversity and complexity of kelpforest food webs (Byrnes et al. 2011).

\section{Subregional dynamics}

Environmental conditions vary substantially within the Santa Barbara Channel. As a result, the regional comparison of kelp biomass to physical variables may be confounded by subregions that are controlled by different physical forcings. We found that subregions with different wave 
exposures responded differently to variations in wave heights and SST (Table 2). The dynamics of the relatively sheltered mainland coastline south of Point Conception (Subregion D) were significantly negatively correlated with SST, but not maximum wave height. Tegner et al. (1996) observed similar behavior in the Point Loma kelp forest near San Diego: a measure of canopy density was significantly negatively correlated with SST but not wave heights. Also, in many years, minimum canopy biomass levels occurred in late summer-early fall for Subregion D (Fig. 9). This is generally a time of relatively low wave energy and low nutrient levels, suggesting that senescence unrelated to waves is causing these annual minimums. The large variation in the timing of annual maximums and minimums for Subregion D results from variability in the timing of storms large enough to affect this sheltered region as well as temporal variability in nutrient conditions each year.

Our results indicate that Point Conception marks a major biogeographic boundary for the seasonal dynamics of giant-kelp forests in California. Changes in kelp biomass along the exposed coastline north of Point Conception were well-correlated with wave height, but not SST as high storm mortalities were observed each winter. This created a pronounced and predictable seasonal cycle with lower interannual variability than the more sheltered subregions to the south (Fig. 9). The high variation in canopy biomass observed in October and November (e.g. long boxes in Fig. 9A) reflect variability in the timing of the onset of the winter storm season. Relatively high nutrient conditions in this subregion likely allowed for consistent spring and summer recovery each year (Jackson 1987). This result agrees with those of Donnellan (2004), who found that seasonal canopy dynamics of exposed central Californian kelp beds were highly regular and predictable. The subregions containing the Santa Barbara Channel Islands represented a combination of more complex exposure and nutrient conditions. Seasonality of kelp biomass in Subregion B was similar to that of the exposed Subregion A, but Subregion B displayed a higher variability in the timing of annual minimums that was likely due to the higher variability of exposures contained in this subregion. Subregion B showed consistent spring recovery each year, probably reflecting the fact that biomass dynamics of this subregion are rarely limited by nutrients. Like the coastline north of Point Conception, the south sides of the 2 westernmost Channel Islands are typically bathed in nutrientrich water (Otero \& Siegel 2004, McPhee-Shaw et al. 2007).

Previous studies have shown fluctuations in kelp abundance on cycles of 3 to $5 \mathrm{yr}$ and have suggested that these fluctuations result from seasonal forcings such as wave disturbance (Dayton et al. 1984, Graham et al. 1997). Nisbet \& Bence (1989) developed a family of 2-stage kelp population models (juvenile and adults) that reproduced 3 to $5 \mathrm{yr}$ cycles as well as shorterperiod 1 yr cycles. Their models were based on the idea that population dynamics are driven by recruitment events, which are in turn controlled by temperature, bottom irradiance, and unknown stochastic factors. Their models predicted that larger seasonal fluctuations in surface irradiance and adult mortality, such as those driven by wave disturbance, should lead to more regular annual recruitment as mortality of adults each year frees up space and resources (i.e. light) for new recruits. On a regional scale, we found that exposed coastlines experienced more regular annual cycles of winter mortality and spring recovery than did sheltered regions. Our observation of greater regularity of the annual cycles in exposed regions is in contrast to that observed by Graham et al. (1997) in central California and may reflect differences in the spatial scales over which kelp was measured in the 2 studies (i.e. $\mathrm{m}^{2}$ in Graham et al. 2007 vs. $\mathrm{km}^{2}$ in the present study). The dynamics of giant kelp at fieldtransect scales do not always reflect dynamics at the forest or regional scales (Cavanaugh et al. 2010).

The present work represents the most spatially and temporally comprehensive analysis of the drivers of giant-kelp biomass to date. We have shown that there is a large amount of regional heterogeneity in the response of kelp biomass to different environmental factors, demonstrating that conclusions drawn from local studies cannot always be applied to regional scales. The roles of environmental drivers of kelp biomass also vary in time, making it difficult to predict the response of this system to future changes in environmental conditions. Continued large-scale and longterm observations are needed to better our understanding of how ecosystems may behave differently in a future climate.

Acknowledgements. We acknowledge the support of the NASA Biodiversity and Ecological Forecasting Science program, NASA's support of K.C.C. through the Earth System Science fellowship program, and the National Science Foundation's support of the Santa Barbara Coastal Long Term Ecological Research (SBC LTER) site. We thank the numerous SBC LTER divers for collection of data in the field. M. Graham and 2 anonymous reviewers provided valuable comments on the manuscript.

\section{LITERATURE CITED}

Adams J, Smith M, Gillespie A (1993) Im aging spectroscopy: interpretation based on spectral mixture analysis. In: Pieters CM, Englert P (eds) Remote geochemical analysis: elemental and mineralogical composition. Cambridge University Press, New York, NY, p 145-166 
Adams P, Inman D, Graham N (2008) Southern California deep-water wave climate: characterization and application to coastal processes. J Coast Res 24:1022-1035

Baardseth E (1970) A square-scanning, two stage sampling method of estimating seaweed quantities. Rep Norw Inst Seaweed Res 33:1-41

Baugh W, Groeneveld D (2008) Empirical proof of the empirical line. Int J Remote Sens 29:665-672

Behrenfeld M, O'Malley R, Siegel D, McClain C and others (2006) Climate-driven trends in contemporary ocean productivity. Nature 444:752-755

> Berk A, Bernstein L, Anderson G, Acharya P, Robertson D, Chetwynd J, Adler-Golden S (1998) MODTRAN cloud and multiple scattering upgrades with application to AVIRIS. Remote Sens Environ 65:367-375

Britton-Simmons K, Eckman JE, Duggins DO (2008) Effect of tidal currents and tidal stage on estimates of bed size in the kelp Nereocystis luetkeana. Mar Ecol Prog Ser 355:95-105

Bromirski P, Flick R, Cayan D (2003) Storminess variability along the California coast: 1858-2000. J Clim 16:982-993

Byrnes JE, Reed DC, Cardinale BJ, Cavanaugh KC, Holbrook SJ, Schmitt RJ (2011) Climate-driven increases in storm frequency simplify kelp forest food webs. Glob Change Biol (in press) doi:10.1111/j.1365-2486.2011.02409.x

> Cavanaugh KC, Siegel DA, Kinlan BP, Reed DC (2010) Scaling giant kelp field measurements to regional scales using satellite observations. Mar Ecol Prog Ser 403:13-27

Clendenning KA, Sargent MC (1971) Photosynthesis and general development in Macrocystis. Nova Hedwigia 32: 169-190

- Dayton P, Tegner M (1990) Bottoms beneath troubled waters: benthic impacts of the 1982-1984 El Niño in the temperature zone. Elsevier Oceanogr Ser 52:433-472

> Dayton P, Currie V, Gerrodette T, Keller B, Rosenthal R, Van Tresca D (1984) Patch dynamics and stability of some California kelp communities. Ecol Monogr 54:253-289

> Dayton P, Tegner M, Parnell P, Edwards P (1992) Temporal and spatial patterns of disturbance and recovery in a kelp forest community. Ecol Monogr 62:421-445

> Dayton P, Tegner M, Edwards P, Riser K (1999) Temporal and spatial scales of kelp demography: the role of oceanographic climate. Ecol Monogr 69:219-250

> Dennison P, Roberts D (2003a) The effects of vegetation phenology on endmember selection and species mapping in southern California chaparral. Remote Sens Environ 87: 295-309

> Dennison P, Roberts D (2003b) Endmember selection for multiple endmember spectral mixture analysis using endmember average RMSE. Remote Sens Environ 87:123-135

> Deysher L (1993) Evaluation of remote sensing techniques for monitoring giant kelp populations. Hydrobiologia 260-261: 307-312

> Deysher L, Dean T (1986) In situ recruitment of sporophytes of the giant kelp Macrocystis pyrifera (L.) C.A. Agardh: effects of physical factors. J Exp Mar Biol Ecol 103:41-63

Di Lorenzo E, Schneider N, Cobb K, Franks P and others (2008) North Pacific Gyre Oscillation links ocean climate and ecosystem change. Geophys Res Lett 35:L08607 doi: 10.1029/2007GL032838

- Doney S, Fabry V, Feely R, Kleypas J (2009) Ocean acidification: the other $\mathrm{CO}_{2}$ problem. Annu Rev Mar Sci 1:169-192

Donnellan M (2004) Spatial and temporal variability of kelp forest canopies in central California. MS thesis, San Jose State University, San Jose, CA

Easterling D, Meehl G, Parmesan C, Changnon S, Karl T, Mearns L (2000) Climate extremes: observations, modeling, and impacts. Science 289:2068-2074
Edwards MS (2004) Estimating scale-dependency in disturbance impacts: El Niños and giant kelp forests in the northeast Pacific. Oecologia 138:436-447

Fram J, Stewart H, Brzezinski M, Gaylord B, Reed D, Williams S, MacIntyre S (2008) Physical pathways and utilization of nitrate supply to the giant kelp, Macrocystis pyrifera. Limnol Oceanogr 53:1589-1603

Furby S, Campbell N (2001) Calibrating images from different dates to 'like-value' digital counts. Remote Sens Environ 77:186-196

> Graham MH, Harrold C, Lisin S, Light K, Watanabe JM, Foster MS (1997) Population dynamics of giant kelp Macrocystis pyrifera along a wave exposure gradient. Mar Ecol Prog Ser 148:269-279

Graham M, Vasquez J, Buschmann A (2007) Global ecology of the giant kelp Macrocystis: from ecotypes to ecosystems. Oceanogr Mar Biol Annu Rev 45:39-88

> Harley C, Randall Hughes A, Hultgren K, Miner B and others (2006) The impacts of climate change in coastal marine systems. Ecol Lett 9:228-241

> Harms S, Winant C (1998) Characteristic patterns of the circulation in the Santa Barbara Channel. J Geophys Res 103: 3041-3065

Hickey B (1979) The California current system-hypotheses and facts. Prog Oceanogr 8:191-279

Hoegh-Guldberg O, Bruno J (2010) The impact of climate change on the world's marine ecosystems. Science 328: 1523-1528

> Huth R (1996) An intercomparison of computer-assisted circulation classification methods. Int J Climatol 16:893-922

Jackson G (1987) Modelling the growth and harvest yield of the giant kelp Macrocystis pyrifera. Mar Biol 95:611-624

Jensen JR, Estes JE, Tinney L (1980) Remote sensing techniques for kelp surveys. Photogramm Eng Remote Sensing 46:743-755

> Lee D, Storey J, Choate M, Hayes R (2004) Four years of Landsat-7 on-orbit geometric calibration and performance. IEEE Trans Geosci Remote Sens 42:2786-2795

Legendre P, Legendre L (1998) Numerical ecology, 2nd English edn. Elsevier Science, Amsterdam

> Li L, Ustin S, Lay M (2005) Application of multiple endmember spectral mixture analysis (MESMA) to AVIRIS imagery for coastal salt marsh mapping: a case study in China Camp, CA, USA. Int J Remote Sens 26:5193-5207

- Mantua N, Hare S, Zhang Y, Wallace J, Francis R (1997) A Pacific interdecadal climate oscillation with impacts on salmon production. Bull Am Meteorol Soc 78:1069-1079

> Markham B, Storey J, Williams D, Irons J (2004) Landsat sensor performance: history and current status. IEEE Trans Geosci Remote Sens 42:2691-2694

McPhee-Shaw EE, Siegel DA, Washburn L, Brzezinski MA, Jones JL, Leydecker A, Melack J (2007) Mechanisms for nutrient delivery to the inner shelf: observations from the Santa Barbara Channel. Limnol Oceanogr 52: 1748-1766

Meehl G, Zwiers F, Evans J, Knutson T, Mearns L, Whetton P (2000) Trends in extreme weather and climate events: issues related to modeling extremes in projections of future climate change. Bull Am Meteorol Soc 81:427-436

Meehl G, Stocker T, Collins W, Friedlingstein P and others (2007) Global climate projections. In: Qin D, Manning M, Chen Z, Marquis M, Averyt K, Tignor M, Miller HL (eds) Climate change 2007: the physical science basis. Contribution of Working Group I to the Fourth Assessment Report of the Intergovernmental Panel on Climate Change. Cambridge University Press, New York, NY, p 747-845

Nisbet R, Bence J (1989) Alternative dynamic regimes for 
canopy-forming kelp: a variant on density-vague population regulation. Am Nat 134:377-408

North WJ, Zimmerman RC (1984) Influences of macronutrients and water temperatures on summertime survival of Macrocystis canopies. Hydrobiologia 116-117:419-424

O'Reilly W, Guza R (1993) A comparison of two spectral wave models in the Southern California Bight. Coast Eng 19: 263-282

Okin G, Roberts D, Murray B, Okin W (2001) Practical limits on hyperspectral vegetation discrimination in arid and semiarid environments. Remote Sens Environ 77:212-225

Otero M, Siegel D (2004) Spatial and temporal characteristics of sediment plumes and phytoplankton blooms in the Santa Barbara Channel. Deep-Sea Res II 51:1129-1149

Parnell PE, Miller EF, Lennert-Cody CE, Dayton PK, Carter ML, Stebbins TD (2010) The response of giant kelp (Macrocystis pyrifera) in southern California to low-frequency climate forcing. Limnol Oceanogr 55:2686-2702

Peterson W, Schwing F (2003) A new climate regime in Northeast Pacific ecosystems. Geophys Res Lett 30:1896 doi: 10.1029/2003GL017528

Przeslawski R, Ahyong S, Byrne M, Woerheide G, Hutchings $P$ (2008) Beyond corals and fish: the effects of climate change on noncoral benthic invertebrates of tropical reefs. Glob Change Biol 14:2773-2795

Rassweiler A, Arkema K, Reed D, Zimmerman R, Brzezinski $M$ (2008) Net primary production, growth, and standing crop of Macrocystis pyrifera in southern California. Ecology 89:2068

Reed D, Foster M (1984) The effects of canopy shadings on algal recruitment and growth in a giant kelp forest. Ecology 65:937-948

Reed D, Ebeling A, Anderson T, Anghera M (1996) Differential reproductive responses to fluctuating resources in two seaweeds with different reproductive strategies. Ecology 77:300-316

Reed D, Rassweiler A, Arkema K (2008) Biomass rather than growth rate determines variation in net primary production by giant kelp. Ecology 89:2493-2505

Roberts D, Gardner M, Church R, Ustin S, Scheer G, Green R (1998) Mapping chaparral in the Santa Monica Mountains

Editorial responsibility: Lisandro Benedetti-Cecchi, Pisa, Italy using multiple endmember spectral mixture models. Remote Sens Environ 65:267-279

Rosenzweig C, Karoly D, Vicarelli M, Neofotis P and others (2008) Attributing physical and biological impacts to anthropogenic climate change. Nature 453:353-357

Ruggiero P, Komar P, Allan J (2010) Increasing wave heights and extreme value projections: the wave climate of the US Pacific Northwest. Coast Eng 57:539-552

Seymour R (1998) Effects of El Niños on the west coast wave climate. Shore Beach 66:3-6

Smith CA, Sardeshmukh PD (2000) The effect of ENSO on the intraseasonal variance of surface temperatures in winter. Int J Climatol 20:1543-1557

> Stekoll MS, Deysher LE, Hess M (2006) A remote sensing approach to estimating harvestable kelp biomass. J Appl Phycol 18:323-334

Tegner MJ, Dayton PK, Edwards PB, Riser KL (1996) Is there evidence for long-term climatic change in southern California kelp forests? Calif Coop Ocean Fish Invest Rep 37:111-126. Available at: www.calcofi.org/publications/ ccreports/118-vol37-1996.html

Tegner MJ, Dayton PK, Edwards PB, Riser KL (1997) Largescale, low-frequency oceanographic effects on kelp forest succession: a tale of two cohorts. Mar Ecol Prog Ser 146: $117-134$

Utter B, Denny M (1996) Wave-induced forces on the giant kelp Macrocystis pyrifera (Agardh): field test of a computational model. J Exp Biol 199:2645

> Wernberg T, Thomsen MS, Tuya F, Kendrick GA, Staehr PA, Toohey BD (2010) Decreasing resilience of kelp beds along a latitudinal temperature gradient: potential implications for a warmer future. Ecol Lett 13:685-694

Youngentob K, Roberts D, Held A, Dennison P, Jia X, Lindenmayer D (2011) Mapping two Eucalyptus subgenera using multiple endmember spectral mixture analysis and continuum-removed imaging spectrometry data. Remote Sens Environ 115:1115-1128

Zimmerman RC, Kremer JN (1986) In situ growth and chemical composition of the giant kelp, Macrocystis pyrifera: response to temporal changes in ambient nutrient availability. Mar Ecol Prog Ser 27:277-285

Submitted: December 13, 2010; Accepted: March 21, 2011 Proofs received from author(s): May 5, 2011 